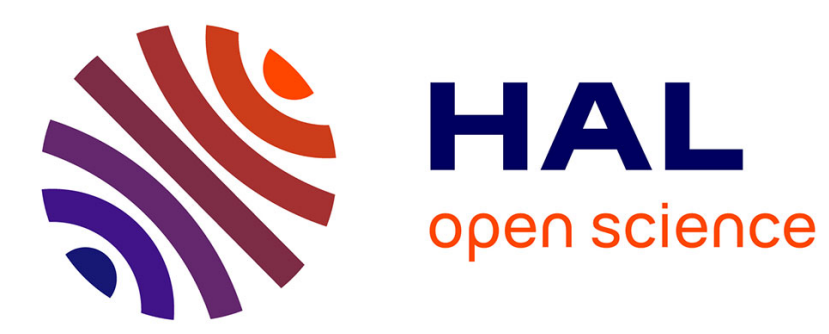

\title{
Structure and rotational dynamics of methyl propionate studied by microwave spectroscopy
}

Ha Vinh Lam Nguyen, Wolfgang Stahl, Isabelle Kleiner

\section{To cite this version:}

Ha Vinh Lam Nguyen, Wolfgang Stahl, Isabelle Kleiner. Structure and rotational dynamics of methyl propionate studied by microwave spectroscopy. Molecular Physics, 2012, 110 (17), pp.2035-2042. 10.1080/00268976.2012.683884 . hal-03183169

\section{HAL Id: hal-03183169 \\ https://hal.science/hal-03183169}

Submitted on 27 Mar 2021

HAL is a multi-disciplinary open access archive for the deposit and dissemination of scientific research documents, whether they are published or not. The documents may come from teaching and research institutions in France or abroad, or from public or private research centers.
L'archive ouverte pluridisciplinaire HAL, est destinée au dépôt et à la diffusion de documents scientifiques de niveau recherche, publiés ou non, émanant des établissements d'enseignement et de recherche français ou étrangers, des laboratoires publics ou privés. 


\title{
Structure and rotational dynamics of methyl propionate studied by microwave spectroscopy
}

Ha Vinh Lam Nguyen ${ }^{a}$, Wolfgang Stahl ${ }^{a}$, and Isabelle Kleiner ${ }^{b}$

${ }^{\text {a } I n s t i t u t e ~ o f ~ P h y s i c a l ~ C h e m i s t r y, ~ R W T H ~ A a c h e n ~ U n i v e r s i t y, ~ L a n d o l t w e g ~ 2, ~ D-52074 ~ A a c h e n, ~}$ Germany

${ }^{\mathrm{b}}$ Laboratoire Interuniversitaire des Systèmes Atmosphériques (LISA), UMR 7583

(CNRS/Univ. Paris Est \& Paris Diderot), Université de Paris Est, 61 avenue du Général de Gaulle, F-94010 Créteil cedex, France

Corresponding author: Ha Vinh Lam Nguyen

Institute of Physical Chemistry
RWTH Aachen University
Landoltweg 2
D-52074 Aachen
Germany
Phone: +49 2418094759
Fax: +4924180 92365
Email: nguyen@pc.rwth-aachen.de

\begin{abstract}
We report on the rotational spectra of the most abundant conformer of methyl propionate, $\mathrm{CH}_{3} \mathrm{CH}_{2} \mathrm{COOCH}_{3}$, recorded with a Fourier transform microwave spectrometer under molecular beam conditions. We present accurate rotational constants and centrifugal distortion constants. For the propionyl $\mathbf{C H}_{3} \mathrm{CH}_{2} \mathrm{CO}$ - methyl group and the methoxy -OCH methyl group barriers of $820.46(99) \mathrm{cm}^{-1}$ and $429.324(23) \mathrm{cm}^{-1}$, respectively, were found. For spectral analysis two different computer programs were used, the code BELGI-C s $_{\text {-2tops }}$ based on the rho axis method (RAM) and the code XIAM based on the combined axis method (CAM). The results are compared. The experimental work was supplemented by quantum chemical calculations. Potential energy functions for the rotation of the terminal methyl groups and also of the entire ethyl group were parametrized.
\end{abstract}

Keywords: methyl propionate, microwave spectroscopy, internal rotation

\section{Introduction}

Methyl propionate, $\mathrm{CH}_{3} \mathrm{CH}_{2} \mathrm{COOCH}_{3}$, is a small aliphatic ester which is found in nature where it contributes to the flavor of fruits. Therefore, it is also used as perfuming agent and for flavoring. Further, it plays an important role as a solvent. Despite its widespread use almost nothing is known about its conformers and its internal dynamics. Only some results on the vibrational spectrum in the liquid and the solid phase have been carried out.[1] We considered thus it worthwhile to study methyl propionate by a combination of molecular beam Fourier transform microwave (MB-FTMW) spectroscopy and quantum chemical calculations.

The rotational spectrum of ethyl acetate [2] was measured using a MB-FTMW spectrometer. It was analyzed using the internal rotor program BELGI-C $\mathrm{C}_{\mathrm{s}}$ [3], taking into account the internal rotation of one of the two methyl groups. We found a barrier to internal rotation of 
the acetyl methyl group of $99.57(11) \mathrm{cm}^{-1}$ which is relatively low in comparison to the barriers usually found for alkyl methyl groups. E.g. for ethyl fluoride [4] a torsional barrier of $1171.3(14) \mathrm{cm}^{-1}$ has been reported. Moreover, methyl acetate has been originally measured by Sheridan et al. [5] and was remeasured and reanalyzed by Tudorie et al. [6] with the new computer code BELGI- $C_{\mathrm{s}}$ for two-top molecules. A similar barrier of $101.740(30) \mathrm{cm}^{-1}$ was found for the acetyl methyl group whereas the methoxy methyl group showed a considerably higher barrier of $422.148(55) \mathrm{cm}^{-1}$. In the case of methyl propionate there are two methyl groups which could show splittings due to internal rotation. We will refer to the $\mathbf{C H}_{3} \mathrm{CH}_{2} \mathrm{CO}-$ methyl group as the propionyl methyl group, the $-\mathrm{OCH}_{3}$ methyl group will be called the methoxy methyl group throughout this text. For the propionyl methyl group we expected a barrier to internal rotation on the order of $800 \mathrm{~cm}^{-1}$, as it was observed in diethyl ketone [7] and methyl ethyl ketone [8]. For the methoxy methyl group we assumed an intermediate barrier on the order of $425 \mathrm{~cm}^{-1}$, as in the case of methyl acetate.

This is the first time that the BELGI-C $\mathrm{C}_{\mathrm{s}}$-2tops code for two-top molecules is applied to a system with one intermediate and one high barrier. The results will be compared with those obtained with the XIAM code [9]. The XIAM code and the BELGI-C $\mathrm{C}_{\mathrm{s}}$ code were compared for several one-top molecules such as ethyl acetate [2], but such a comparison was never done for two-top molecules so far.

\section{Experimental setup}

The rotational spectrum of methyl propionate was recorded with a MB-FTMW spectrometer working in the frequency range between 6 and $26.5 \mathrm{GHz}$. The setup is similar to that described in ref. [10]. Methyl propionate was obtained from Merck Schuchardt, Hohenbrunn, Germany with a stated purity of $\geq 98 \%$ and used without further purification. The nature of the impurities is unknown. The sample was prepared by mixing methyl propionate with helium to obtain a concentration of $1 \%$ by volume. For the pulsed jet, a stagnation pressure of $100 \mathrm{kPa}$ was used.

In a first step broadband scans were taken (see Figure 1) and the spectral lines were subsequently remeasured in the high resolution mode of the spectrometer. The line widths were usually from 20 to $25 \mathrm{kHz}$. Due to the broadened lines the estimated accuracy of the line position for isolated lines is approximately $4 \mathrm{kHz}$. For more details see ref. [7].

\section{Quantum chemical calculations}

Before the microwave spectrum was recorded, we started our study on methyl propionate with quantum chemical calculations to determine the possible conformers. These calculations are always helpful for the structure determination of large molecules where classical methods like isotopic substitution turn out to be difficult.

By rotating the entire $-\mathrm{OCH}_{3}$ group around the $\mathrm{C}_{3}-\mathrm{O}_{5}$ bond, trans and cis conformers can be generated (see Figure 2, for atom numbers see the trans $\mathrm{C}_{\mathrm{s}}$ conformer). Theoretical studies [11] and also our own observations on ethyl acetate [2] have shown that cis esters are usually much higher in energy than trans esters. Therefore, cis esters are unlikely to be observed under molecular beam conditions and we decided to concentrate on the trans ester throughout this study.

As a next step, the ethyl group was rotated around the $\mathrm{C}_{2}-\mathrm{C}_{3}$ bond. A potential curve was calculated where the dihedral angle $\varphi=\angle\left(\mathrm{C}_{1}, \mathrm{C}_{2}, \mathrm{C}_{3}, \mathrm{O}_{5}\right)$ was varied within a $10^{\circ}$ step width while all other geometry parameters were optimized. At the beginning, calculations were carried out at the MP2/6-311++G(d,p) level of theory using the Gaussian03 package [12]. 
The 6-311++G(d,p) basis set was chosen, since it turned out to yield quite reasonable results for some other esters like ethyl acetate [2], allyl acetate [13], isopropenyl acetate [14], and ethyl pivalate [15]. The potential curve is given in Figure 3, the Fourier coefficients of the potential function are available as supplementary material (Table S1). As shown in Figure 3, there are two possible conformers for the trans methyl propionate. Fully optimized structures and frequency calculations showed that both of them are true minima rather than saddle points. The most stable conformer has $\mathrm{C}_{\mathrm{s}}$ symmetry whereas the trans $\mathrm{C}_{1}$ conformer exists as an enantiomeric pair at $\varphi \approx \pm 100^{\circ}$. Another trans configuration with $\mathrm{C}_{\mathrm{s}}$ symmetry at $\varphi=$ $\pm 180^{\circ}$ turned out to be a transition state. It should be noted that the two local minima of the potential curve, which present the trans $\mathrm{C}_{1}$ conformers, are very shallow. The difference between these minima and the next local maxima at $\varphi \approx \pm 80^{\circ}$ is only $0.09 \mathrm{~kJ} / \mathrm{mol}$. Due to the low temperature in the molecular beam the trans $\mathrm{C}_{1}$ conformer is difficult to be seen in the molecular beam, since its stabilization energy is about $2.1 \mathrm{~kJ} / \mathrm{mol}$ above the energy of the most stable trans $\mathrm{C}_{\mathrm{s}}$ conformer. The Cartesian coordinates of both conformers are given in Table S2 in the supplementary material.

After the rotational spectrum has been assigned, some additional quantum chemical calculations were carried out in order to find the most suitable method and basis set to reproduce the observed rotational constants of methyl propionate. Unfortunately, comprehensive quantum chemical studies on esters which focus on the comparison of theoretical and experimental rotational constants have not yet been undertaken. Therefore, we have chosen additional methods and basis sets just based on our current experience. From the quantum chemical calculations on diethyl ketone [7] and ethyl isovalerate [16] we found that in these cases the MP2/6-311++G(d,p) basis set is not in good agreement with the experimental results. Methyl propionate has a similar structure as these two molecules, which is illustrated with bold printed bonds in Figure 4 . The $\mathrm{C}_{2}-\mathrm{C}_{3}$ bond has a low torsional force constant. The correspondent dihedral angle depends strongly on the chosen basis set. Therefore, we decided to repeat all calculations with the 6-31G(d,p) basis set since it turned out to give the best results in the case of ethyl isovalerate [16]. Results of these calculations (see Figure 3) have shown, that the trans $\mathrm{C}_{\mathrm{s}}$ conformer at $\varphi=0^{\circ}$ is still the most stable one. The transition state at $\varphi= \pm 180^{\circ}$ has a slightly higher energy, but in between the whole potential curve has changed. The trans $C_{1}$ conformer moved from $\varphi \approx \pm 100^{\circ}$ to $\varphi \approx \pm 120^{\circ}$. The corresponding minima become sharper. The difference to the next local maxima rises to $0.90 \mathrm{~kJ} / \mathrm{mol}$.

Finally, calculations based on density functional theory were carried out. We used the B3LYP functional in combination with the $6-311++\mathrm{G}(\mathrm{d}, \mathrm{p})$ basis set which gave reliable results in the case of diethyl ketone [7]. Here, the potential curve for the rotation around the $\mathrm{C}_{2}-\mathrm{C}_{3}$ bond looks similar to the curve obtained at the MP2/6-311++G(d,p) level, however, the secondary minima are less pronounced but higher in energy. The quantum chemical results will be compared with the experimental data in section 5 .

We also calculated the barrier to internal rotation of both methyl groups by rotating the methyl groups around the $\mathrm{O}_{5}-\mathrm{C}_{6}$ and the $\mathrm{C}_{1}-\mathrm{C}_{2}$ bonds, respectively. These calculations were exclusively performed at the MP2/6-311++G(d,p) level of theory. The data were collected in a $10^{\circ}$ grid and parametrized by Fourier coefficients. These are also given as supplementary material in Table $S 3$. The calculated $V_{3}$ potentials were found to be $509.2 \mathrm{~cm}^{-1}$ and $956.2 \mathrm{~cm}^{-1}$ for the methoxy and the propionyl methyl group, respectively.

\section{Spectral analysis}

\subsection{Microwave spectrum}


At the beginning of our experimental investigation a broadband scan in the frequency range from 9.5 to $12.0 \mathrm{GHz}$ was recorded as shown in Figure 1. Though there are different results by using different methods and basis sets, all quantum chemical calculations yielded two possible conformers of trans methyl propionate. At the MP2/6-311++G(d,p) level, the potential energy of the trans $\mathrm{C}_{1}$ conformer is approximately $2.1 \mathrm{~kJ} / \mathrm{mol}$ higher than that of the trans $\mathrm{C}_{\mathrm{s}}$ conformer. Other quantum chemical calculations predicted even higher energies. $\mathrm{A}$ simple calculation of the Boltzmann factor yields a trans $\mathrm{C}_{1} /$ trans $\mathrm{C}_{\mathrm{s}}$ ratio at room temperature $(298 \mathrm{~K})$ of 0.42 and at an assumed beam temperature of $10 \mathrm{~K}$ a ratio of $1.1 \cdot 10^{-11}$ is found. From Figure 3 it can be seen that the activation energy for the trans $\mathrm{C}_{1}$ to trans $\mathrm{C}_{\mathrm{s}}$ conversion is less than $1 \mathrm{~kJ} / \mathrm{mol}$. Therefore, the conversion process during the expansion in the nozzle is very fast and effective and it appears unlikely that the trans $\mathrm{C}_{1}$ conformer can still be observed in the beam. Consequently, only rotational lines of the trans $\mathrm{C}_{\mathrm{s}}$ conformer should be present in the spectrum. Figure 1 shows some strong lines and many lines with much lower intensity. We attribute the low intensity lines to ${ }^{13} \mathrm{C}$ isotopologues with the possibility for the ${ }^{13} \mathrm{C}$ atom to go at four different places within the molecule and decided to use only the intensive lines to assign the trans $\mathrm{C}_{\mathrm{s}}$ main conformer.

There are two methyl groups in methyl propionate which show internal rotation. It was clear that the torsion of the methoxy methyl group should cause a wide splitting into an A and an E component. The A components should be additionally split into two torsional components due to the internal rotation of the propionyl methyl group, which will be labeled as the AA, AE doublets. The E components split into three components which are called the EA, EE, and EE* triplets. Examples for the doublet and the triplet structure are given in Figure 5 and Figure 6, respectively. These local mode symmetry labels are the same as described in ref. [14] and will not be repeated here in detail. The first letter of the symmetry label refers to the methoxy methyl group, the second letter to the propionyl methyl group. Since the torsional barrier of the propionyl methyl group is higher than that one of the methoxy methyl group, the splittings caused by the propionyl methyl group should be much narrower. It should be noted that in all calculations using BELGI- $\mathrm{C}_{\mathrm{s}}$-2tops the symmetry labels are based on the permutation-inversion group $\mathrm{G}_{18}$. For the line designation the local mode symmetry labels correspond to the $\mathrm{G}_{18}$ symmetry labels by $\mathrm{AA} \leftrightarrow \mathrm{A} 1 / \mathrm{A} 2, \mathrm{AE} \leftrightarrow \mathrm{E} 1, \mathrm{EA} \leftrightarrow \mathrm{E} 2, \mathrm{EE} \leftrightarrow \mathrm{E} 3$, and $\mathrm{EE}^{*} \leftrightarrow \mathrm{E} 4$.

From quantum chemical calculations the rotational constants and also internal rotation parameters were roughly known. We used the rotational constants from the MP2/6-311++G(d,p) calculation to predict the AA species lines with a rigid rotor program and could assign all AA components within the broadband scan (Figure 1). In a next step, the XIAM code was used to predict a complete spectrum with all torsional components using the expected barriers of $\mathrm{V}_{3}=425 \mathrm{~cm}^{-1}$ and $800 \mathrm{~cm}^{-1}$ for the methoxy and the propionyl methyl group, respectively. The theoretical spectrum predicted an AA-EA splitting in the order of a few $\mathrm{MHz}$, whereas the AA-AE and the EA-EE-EE* splittings are only a few ten kHz. All lines were remeasured in the high resolution mode.

Finally, the same set of transitions was fitted using the BELGI-C $\mathrm{C}_{\mathrm{s}}-2$ tops code. Lines were weighted in the least squares fit (as usual) by the inverse of the square of the estimated measurement error of $4 \mathrm{kHz}$. In total, 61 transitions with 282 torsional components were fitted for the ground torsional state $\mathrm{v}_{\mathrm{t}}=0$ of the trans $\mathrm{C}_{\mathrm{s}}$ methyl propionate molecule.

\subsection{The XIAM and the BELGI-C $\mathrm{C}_{\mathrm{s}}-2$ tops codes}

In this study we used two different codes which can deal with a two-top internal rotor molecule spectrum. The first code is XIAM which has been described several times in the 
literature [9]. XIAM is a combined axis method (CAM) which sets up the rotation-torsion Hamiltonian in the rho-axis system (RAM) for each top, than converts the RAM parameters into principal axis system (PAM) parameters.

The second code, BELGI-C $\mathrm{C}_{\mathrm{s}}$-2tops, has been recently developed to fit the high-resolution torsion-rotation spectra of molecules with two inequivalent methyl rotors and a plane of symmetry at equilibrium. This program was applied to methyl acetate, $\mathrm{CH}_{3} \mathrm{COOCH}_{3}$, [6] and allowed us to reproduce more than 800 microwave and millimeter-wave measurements on ground-state transitions for this molecule, leading to root-mean-square deviations of $4 \mathrm{kHz}$ for the microwave lines and of $40 \mathrm{kHz}$ for the millimeter-wave lines, i.e., to residuals essentially equal to the experimental measurement errors.

As described in ref. [6], the BELGI-C $\mathrm{C}_{\mathrm{s}}-2$ tops program is closely related to a program for fitting the microwave spectrum of $\mathrm{N}$-methylacetamide, $\mathrm{CH}_{3} \mathrm{NH}(\mathrm{C}=\mathrm{O}) \mathrm{CH}_{3}$ [17], which has been used only for this special purpose. We differ from the code used in ref. [17] mainly by the fact that we adopted a two-step diagonalization procedure in order to have a faster code. The two-step diagonalization procedure is similar to that one used by Herbst et al. [18]. However, we differ from it by using a "modified PAM" [19], instead of the RAM approach [6], which requires placing the $z$ axis nearly parallel to "the" top axis. The PAM approach is well suited to problems with small $\rho$ values [19] as methyl propionate.

In the first step, only the lowest order pure torsional operators of the Hamiltonian are considered (see eq. (3) of ref. [6] and eq. (6) of ref. [17])

$$
\begin{aligned}
H_{t o r} & =\left[F_{1} p_{\alpha 1}^{2}+(1 / 2) V_{31}\left(1-\cos 3 \alpha_{1}\right)+F_{2} p_{\alpha 2}{ }^{2}+(1 / 2) V_{32}\left(1-\cos 3 \alpha_{2}\right)\right]+F_{12} p_{\alpha 1} p_{\alpha 2} \\
& +V_{12 s} \sin 3 \alpha_{1} \sin 3 \alpha_{2}+V_{12 c}\left(1-\cos 3 \alpha_{1}\right)\left(1-\cos 3 \alpha_{2}\right),
\end{aligned}
$$

where the subscripts 1 and 2 designate the two inequivalent tops, respectively.

The basis set for our first (torsional) diagonalization step consists of products of exponentials of the form $(2 \pi)^{-1} \exp \left(3 k_{1}+\sigma_{1}\right) i \alpha_{1} \exp \left(3 k_{2}+\sigma_{2}\right) i \alpha_{2}$ with the integers $\left|k_{1}\right|$ and $\left|k_{2}\right|$ both less than a basis set cutoff parameter ktronc. In the present calculation, like for methyl acetate, we set ktronc $=10$, which means that 441 torsional basis functions are used in this first step. Following this diagonalization, we kept the lowest $42=(2 k t r o n c+1) \times 2$ torsional energy levels and wave functions for use in the second step. This corresponds (for similar torsional ladders in the two tops) to keeping somewhat more than the first six torsional levels for each top, together with all their combination levels.

The second step of the procedure consists of diagonalizing the rest of the torsion-rotation Hamiltonian (i.e. $H_{r o t}+H_{t o r-r o t}$ described in eq. (6) of ref. [17]). As explained in ref. [6], terms in this Hamiltonian can be constructed by taking symmetry-allowed and Hermitian products of a rotational factor (chosen from operators of the form $J_{x}{ }^{n} J_{y}{ }^{m} J_{z}{ }^{s}$, where $m, n$, and $s$ are integer exponents) and a torsional factor for each top $i=1,2$ (constructed in turn from products of operators of the form $P_{\alpha i}{ }^{m}, \cos 3 n \alpha_{i}, \sin 3 s \alpha_{i}$, where $m, n$, and $s$ again represent integers). Details of the calculation are given in ref. [6] and we will not repeat them here.

\section{Results and discussion}

The 282 torsional components for methyl propionate were fitted with the XIAM code, floating the rotational parameters $\mathrm{A}, \mathrm{B}, \mathrm{C}, \Delta_{\mathrm{J}}, \Delta_{\mathrm{JK}}, \Delta_{\mathrm{K}}, \delta_{\mathrm{J}}, \delta_{\mathrm{K}}$, the two barrier heights $\mathrm{V}_{3,1}$ and $\mathrm{V}_{3,2}$ for each top, the angles $\angle\left(\mathrm{i}_{1}, \mathrm{a}\right)$ and $\angle\left(\mathrm{i}_{2}, \mathrm{a}\right)$ between the two methyl rotors and the principal $a$ axis, and two higher order parameters $\mathrm{D}_{\text {pi2J,1 }}$ and $\mathrm{D}_{\text {pi2-, }}$, while the moment of inertia of the two tops $I_{\alpha, 1}$ and $I_{\alpha, 2}$ values were kept fixed. For the definitions of $D_{\text {pi2J,1 }}$ and $D_{\text {pi2-, } 1}$ see ref. [20], equation 6 , with $D_{\text {pi2J }}=\Delta_{\mathrm{Jm}}$ and $\mathrm{D}_{\text {pi2- }}=\delta_{\mathrm{m}}$. They can be considered as 
centrifugal distortion terms involving the angular momentum of the methoxy methyl rotor. The molecular parameters from the XIAM code are shown in the third column of Table 1. They allow us to reproduce the data with a root-mean-square (rms) deviation of $3.4 \mathrm{kHz}$, close to experimental accuracy.

The BELGI-C $\mathrm{C}_{\mathrm{s}}$-2tops code provides a fit with similar quality $(\mathrm{rms}=3.3 \mathrm{kHz})$ floating 12 parameters, the rotational and 4 centrifugal distorsion parameters $\left(A, B, C, D_{J}, D_{J K}, D_{K}, \delta_{J}\right)$, the two barrier heights $V_{31}$ and $V_{32}$, one $J(J+1)$ dependence $\left(V_{32 J}\right)$, as well as the rotationtorsion coupling term $q_{1}$ which multiplies the operator $\mathrm{J}_{\mathrm{Z}} \mathrm{p}_{1}$ (equivalent to the term $-2 F_{1} \rho_{1 a}$ for top 1 term in the RAM approach) and $r_{1}$ which multiplies the operator $\mathrm{J}_{\mathrm{x}} \mathrm{p}_{1}$ (equivalent to the term $\left.-2 F_{1} \rho_{l b}\right)$. The internal rotation constants for top $1\left(F_{1}\right)$ and for top $2\left(F_{2}\right)$ are kept fixed to values derived from XIAM. The internal rotation constant $F_{12}$, (multiplying the top-top kinetic energy interaction operator $\mathrm{p}_{1} \mathrm{p}_{2}$ was fixed to a value of $-0.50 \mathrm{~cm}^{-1}$ derived from the structure (see eqs. 10-14 of ref. [17]) whereas the two top-top interaction constants of the next higher order in the potential energy $\left(V_{12 s}\right.$ and $\left.V_{12 c}\right)$ were fixed to zero. Qualitatively speaking, these low order potential energy constants could not all be determined because the present data set only contains information on the torsional ground state, and because the two torsional barriers are rather high ( $s=4 V_{3} / 9 F \approx 34$ and 65 for top 1 and 2 , respectively). Getting a convergence for the fit was difficult with the BELGI code using the present data set, due to the high correlation existing between the various parameters, especially between $V_{31}, V_{32}, q_{1}$, $r_{1}, q_{2}$, and $r_{2}$. After a number of trials, we decided to keep the $q_{2}$ and $r_{2}$ parameters fixed (which correspond to the top with the higher barrier and smaller internal rotation splittings) to values calculated from the quantities $-2 F_{2} \rho_{2 a}$ and $-2 F_{2} \rho_{2 b}$, respectively, using the direction cosine from the XIAM code. Our best fit was however obtained for a value of the $q_{2}$ parameter slightly smaller. The set of parameters used to get our final fit is shown in Table 2 .

The list of frequencies fitted with the BELGI-C $\mathrm{C}_{\mathrm{s}}$-2tops code and XIAM, along with the residuals, are given in Table $\mathrm{S} 4$. We found the barrier of the methoxy methyl group of $429.324(23) \mathrm{cm}^{-1}$ to be in good agreement with the assumed barrier of $422.148(55) \mathrm{cm}^{-1}$ reported for methyl acetate [6]. Also the barrier of 820.46(99) $\mathrm{cm}^{-1}$ of the propionyl methyl group matches the barriers of 795(10) $\mathrm{cm}^{-1}$ and 771.93(27) $\mathrm{cm}^{-1}$ observed for methyl ethyl ketone [8] and diethyl ketone [7], respectively. Comparing the experimental barriers with those obtained by quantum chemical calculations shows that the latter ones are by approximately $16.5 \%$ and $18.6 \%$ too high.

We found that in the case of methyl propionate both programs, BELGI-C $\mathrm{s}_{\mathrm{s}}-2$ tops and XIAM, are suitable to analyze the spectrum almost to experimental accuracy. The rotational constants obtained with both programs reasonably agree, however, they do not agree within the standard errors. Quantum chemical calculations carried out at the MP2/6-311++G(d,p) level of theory yielded in the case of methyl propionate the best results. The ab initio A rotational constant differs by $32.6 \mathrm{MHz}(0.34 \%)$, the $\mathrm{B}$ and $\mathrm{C}$ constant match the experimental values almost exactly with deviations of $-4.5 \mathrm{MHz}(-0.21 \%)$ and $-1.5 \mathrm{MHz}(-0.08 \%)$, respectively. A better agreement cannot be expected since the $a b$ initio data refer to the equilibrium structure whereas the experimental data yield rotational constants for the ground vibrational state and no corrections have been made. In contrast to the case of ethyl isovalerate [16], results from calculations at the MP2/6-31G(d,p) level, where no diffuse functions are included in the basis set, are not as good as the larger basis set $6-311++\mathrm{G}(\mathrm{d}, \mathrm{p})$. The calculated $\mathrm{A}, \mathrm{B}$, and $\mathrm{C}$ rotational constants differ by $80.6 \mathrm{MHz}(0.85 \%),-9.9 \mathrm{MHz}(-0.46 \%)$, and $-3.0 \mathrm{MHz}$ $(-0.17 \%)$, respectively. Moreover, calculations based on density functional theory using the B3LYP functional yielded rotational constants which differ by $-26.6 \mathrm{MHz}(-0.28 \%), 25.4$ $\mathrm{MHz}(1.18 \%)$, and $17.9 \mathrm{MHz}(0.99 \%)$ for A, B, and C, respectively. The A rotational constant can be calculated quite well, however, the errors of $\mathrm{B}$ and $\mathrm{C}$ are too large if compared to 
calculations with the MP2 methods. We conclude that the MP2/6-311++G(d,p) level of theory yielded the best results in this case. More extensive interpretation is not yet possible since systematic quantum chemical investigations are currently not available, and the best method and basis sets to calculate the geometry of esters have still to be found by trial and error for individual molecules.

The centrifugal distortion constants $\Delta_{\mathrm{J}}, \Delta_{\mathrm{JK}}, \Delta_{\mathrm{K}}$, and $\delta_{\mathrm{J}}$ of XIAM and $D_{J}, D_{J K}, D_{K}$, and $\delta_{J}$ of BELGI-C $\mathrm{C}_{\mathrm{s}}$-2tops refer to different coordinate systems and cannot be directly compared. No attempts were made to obtain these constants by quantum chemical calculations.

As mentioned before, quite a number of lines are still unassigned. Many of them are very weak, however, there are also a few stronger lines which do not belong to the $\mathrm{C}_{\mathrm{s}}$ conformer. They might be due to impurities of the sample. The four ${ }^{13} \mathrm{C}$ mono-substituted isotopologues of methyl propionate visible in natural concentration will be subject of further investigation.

\section{Acknowledgments}

We thank Nadine Daleiden and Maryam Peymandar for their contribution within a student research project. Funds of the Land Nordrhein-Westfalen and free computer time provided by the Center for Computing and Communication of the RWTH Aachen University are greatly acknowledged. We are also indebted to the European associated laboratory LEA-HIRES for funds. The authors also wish to thank the HPC PROCOPE funding for travel grants.

\section{References}

[1] R. Moravie and J. Corset, Chem. Phys. Lett. 26, 210 (1974).

[2] D. Jelisavac, D.C. Cortés Gómez, H.V.L. Nguyen, L.W. Sutikdja, W. Stahl, I. Kleiner, J. Mol. Spectrosc. 257, 111 (2009).

[3] J.T. Hougen, I. Kleiner, M. Godefroid, J. Mol. Spectrosc. 163, 559 (1994).

[4] E. Fliege, H. Dreizler, J. Demaison, D. Boucher, J. Burie, A. Dubrulle, J. Chem. Phys. 78, 3541 (1983).

[5] J. Sheridan, W. Bossert, A. Bauder, J. Mol. Spectrosc. 80, 1 (1980).

[6] M. Tudorie, I. Kleiner, J. T. Hougen, S. Melandri, L. W. Sutikdja, W. Stahl, J. Mol. Spectrosc. 269, 211(2011).

[7] H. V. L. Nguyen and W. Stahl, Chem. Phys. Chem. 12, 1900 (2011).

[8] N. M. Pozdeev, A. K. Mamleev, L. N. Gunderova, R. V. Galeev, J. Struct. Chem. 29, 52 (1988).

[9] H. Hartwig and H. Dreizler, Z. Naturforsch. 51a, 923 (1996).

[10] J.-U. Grabow, W. Stahl, H. Dreizler, Rev. Sci. Instrum. 67, 4072 (1996).

[11] M. Oki, H. Nakanishi, Bul. Chem. Soc. Japan 43, 2558 (1970).

[12] Gaussian 03, Revision E.01, M. J. Frisch, G. W. Trucks, H. B. Schlegel, G. E. Scuseria, M. A. Robb, J. R. Cheeseman, J. A. Montgomery, Jr., T. Vreven, K. N. Kudin, J. C. Burant, J. M. Millam, S. S. Iyengar, J. Tomasi, V. Barone, B. Mennucci, M. Cossi, G. Scalmani, N. Rega, G. A. Petersson, H. Nakatsuji, M. Hada, M. Ehara, K. Toyota, R. Fukuda, J. Hasegawa, M. Ishida, T. Nakajima, Y. Honda, O. Kitao, H. Nakai, M. Klene, X. Li, J. E. Knox, H. P. Hratchian, J. B. Cross, V. Bakken, C. Adamo, J. Jaramillo, R. Gomperts, R. E. Stratmann, O. Yazyev, A. J. Austin, R. Cammi, C. Pomelli, J. W. Ochterski, P. Y. Ayala, K. Morokuma, G. A. Voth, P. Salvador, J. J. Dannenberg, V. G. Zakrzewski, S. Dapprich, A. D. Daniels, M. C. Strain, O. Farkas, D. K. Malick, A. D. Rabuck, K. Raghavachari, J. B. Foresman, J. V. Ortiz, Q. Cui, A. G. Baboul, S. Clifford, J. Cioslowski, B. B. Stefanov, G. Liu, A. 
Liashenko, P. Piskorz, I. Komaromi, R. L. Martin, D. J. Fox, T. Keith, M. A. AlLaham, C. Y. Peng, A. Nanayakkara, M. Challacombe, P. M. W. Gill, B. Johnson, W. Chen, M. W. Wong, C. Gonzalez, and J. A. Pople, Gaussian, Inc., Wallingford CT, 2004.

[13] H. V. L. Nguyen, H. Mouhib, W. Stahl, I. Kleiner, Mol. Phys. 108, 763 (2010).

[14] H. V. L. Nguyen, W. Stahl, J. Mol. Spectrosc. 264, 120 (2010).

[15] H. Mouhib, Y. Zhao, W. Stahl, J. Mol. Spectrosc. 261, 59 (2010).

[16] H. Mouhib, D. Jelisavac, L. W. Sutikdja, E. Isaak, W. Stahl, J. Phys. Chem. A 115, 118 (2011).

[17] N. Ohashi, J. T. Hougen, R. D. Suenram, F. J. Lovas, Y. Kawashima, M. Fujitake, J. Pyka, J. Mol. Spectrosc. 227, 28 (2004).

[18] E. Herbst, J. K. Messer, F. C. DeLucia, and P. Helminger, J. Mol. Spectrosc. 108, 42 (1984).

[19] C. C. Lin and J.D. Swalen, Rev. Mod. Phys. 31, 841 (1959).

[20] N. Hansen, H. Mäder, T. Bruhn, Mol. Phys. 97, 587 (1999). 


\section{Tables}

Table 1. Spectroscopic constants of methyl propionate referred to the PAM system.

\begin{tabular}{|c|c|c|c|c|c|}
\hline Constant & Unit & XIAM & BELGI-C $_{\mathrm{s}-2 t o p s^{a}}$ & Calc. $^{b}$ & Exp. $^{c}-$ Calc. (\%) \\
\hline A & $\mathrm{GHz}$ & $9.515022(35)$ & $9.51687(21)$ & 9.4824 & $0.0326(0.34 \%)$ \\
\hline B & $\mathrm{GHz}$ & $2.147746(40)$ & $2.148733(52)$ & 2.1522 & $-0.0045(-0.21 \%)$ \\
\hline $\mathrm{C}$ & $\mathrm{GHz}$ & $1.811769(35)$ & $1.814411(45)$ & 1.8133 & $-0.0015(-0.08 \%)$ \\
\hline$\Delta_{\mathrm{J}}$ & $\mathrm{kHz}$ & $0.18577(87)$ & $0.18527(61)$ & & \\
\hline$\Delta_{\mathrm{JK}}$ & $\mathrm{kHz}$ & $0.9968(72)$ & & & \\
\hline$\Delta_{\mathrm{K}}$ & $\mathrm{kHz}$ & $4.936(40)$ & & & \\
\hline$\delta_{\mathrm{J}}$ & $\mathrm{kHz}$ & $0.02803(16)$ & & & \\
\hline$\delta_{\mathrm{K}}$ & $\mathrm{kHz}$ & $-0.271(22)$ & & & \\
\hline $\mathrm{V}_{3,1}$ & $\mathrm{~cm}^{-1}$ & $429.324(23)$ & $428.537(15)$ & 509.2 & $-79.9(-18.6 \%)$ \\
\hline $\mathrm{I}_{\alpha, 1}$ & $\mathrm{u} \AA^{2}$ & 3.15862 (fixed) $^{d}$ & $3.19871(70)$ & 3.217 & \\
\hline$\angle\left(\mathrm{i}_{1}, \mathrm{a}\right)$ & $\circ$ & $156.356(19)$ & $154.827(21)$ & 149.86 & 6.50 \\
\hline$\angle\left(\mathrm{i}_{1}, \mathrm{~b}\right)$ & $\circ$ & $66.356(19)$ & $64.827(21)$ & 59.86 & 6.50 \\
\hline$\angle\left(\mathrm{i}_{1}, \mathrm{c}\right)$ & $\circ$ & $90.0 \quad{\text { (fixed })^{\mathrm{e}}}$ & 90.0 (fixed) & 90.00 & \\
\hline $\mathrm{D}_{\text {pi2J,1 }}$ & $\mathrm{kHz}$ & $27.7(29)$ & & & \\
\hline $\mathrm{D}_{\mathrm{pi} 2-, 1}$ & $\mathrm{kHz}$ & $-70.6(13)$ & & & \\
\hline $\mathrm{s}_{1}$ & & 33.8215 (derived) & 33.7595 & & \\
\hline $\mathrm{V}_{3,2}$ & $\mathrm{~cm}^{-1}$ & $820.46(99)$ & $819.97(25)$ & 956.2 & $-135.7(-16.5 \%)$ \\
\hline $\mathrm{I}_{\alpha, 2}$ & $\mathrm{u} \AA^{2}$ & 3.15862 (fixed) $^{\mathrm{d}}$ & $3.25155(11)$ & 3.161 & \\
\hline$\angle\left(\mathrm{i}_{2}, \mathrm{a}\right)$ & $\circ$ & $32.53(46)$ & $34.4583(22)$ & 33.83 & -1.30 \\
\hline$\angle\left(\mathrm{i}_{2}, \mathrm{~b}\right)$ & $\circ$ & $57.46(46)$ & $55.5417(22)$ & 56.17 & 1.29 \\
\hline$\angle\left(\mathrm{i}_{2}, \mathrm{c}\right)$ & $\circ$ & $90.0 \quad{\text { (fixed })^{\mathrm{e}}}$ & 90.0 (fixed) & 89.95 & \\
\hline $\mathrm{s}_{2}$ & & 65.0381 (derived) & 64.9988 & & \\
\hline$\sigma / N^{f}$ & $\mathrm{kHz}$ & $3.4 / 282$ & $3.3 / 282$ & & \\
\hline$\sigma_{\mathrm{A}} / \mathrm{N}_{\mathrm{A}}^{\mathrm{g}}$ & $\mathrm{kHz}$ & & $3.4 / 55$ & & \\
\hline$\sigma_{\mathrm{E} 1} / \mathrm{N}_{\mathrm{E} 1}$ & $\mathrm{kHz}$ & & $2.6 / 55$ & & \\
\hline$\sigma_{\mathrm{E} 2} / \mathrm{N}_{\mathrm{E} 2}$ & $\mathrm{kHz}$ & & $3.6 / 58$ & & \\
\hline$\sigma_{\mathrm{E} 3} / \mathrm{N}_{\mathrm{E} 3}$ & $\mathrm{kHz}$ & & $3.4 / 57$ & & \\
\hline$\sigma_{\mathrm{E} 4} / \mathrm{N}_{\mathrm{E} 4}$ & $\mathrm{kHz}$ & & $3.4 / 55$ & & \\
\hline
\end{tabular}

${ }^{\text {a }}$ BELGI-2tops constants are transformed into PAM constants using eqs. 10-14 of [17]

${ }^{\mathrm{b}}$ Calculation at the MP2/6-311++G(d,p) level using the program Gaussian03.

${ }^{\mathrm{c}}$ With respect to the XIAM fit.

${ }^{\mathrm{d}}$ Derived from $\mathrm{F}_{0}=160 \mathrm{GHz}$ (fixed)

${ }^{\mathrm{e}}$ Due to symmetry

${ }^{\mathrm{f}}$ Standard deviation of the fit / total number of lines

${ }^{\mathrm{g}}$ Standard deviation / number of lines of each symmetry species 
Table 2. Spectroscopic constants of methyl propionate obtained with the program BELGI-C $\mathrm{s}^{-}$ 2tops.

\begin{tabular}{lll}
\hline \multicolumn{1}{c}{ Operator $^{\mathbf{a}}$} & Parameter $^{\mathbf{b}}$ & \multicolumn{1}{c}{ Value $^{\mathbf{c}} / \mathbf{c m}^{-1}$} \\
\hline $\mathrm{J}_{\mathrm{z}}{ }^{2}$ & $A$ & $0.3471830(48)$ \\
$\mathrm{J}_{\mathrm{x}}{ }^{2}$ & $B$ & $0.0721304(17)$ \\
$\mathrm{J}_{\mathrm{y}}{ }^{2}$ & $C$ & $0.0605222(15)$ \\
$-\mathrm{J}^{4}$ & $\Delta_{J}$ & $6.180(21) \cdot 10^{-9}$ \\
$-\mathrm{J}^{2} \mathrm{~J}_{\mathrm{z}}{ }^{2}$ & $\Delta_{J K}$ & $30.17(16) \cdot 10^{-9}$ \\
$-\mathrm{J}_{\mathrm{z}}{ }^{2}$ & $\Delta_{K}$ & $167.2(13) \cdot 10^{-9}$ \\
$-2 \mathrm{~J}^{2}\left(\mathrm{~J}_{\mathrm{x}}{ }^{2}-\mathrm{J}_{\mathrm{y}}{ }^{2}\right)$ & $\delta_{J}$ & $0.9294(50) \cdot 10^{-9}$ \\
$\mathrm{p}_{1}{ }^{2}$ & $F_{1}$ & $5.6417^{\mathrm{d}}$ \\
$\mathrm{p}_{2}{ }^{2}$ & $F_{2}$ & $5.60674^{\mathrm{d}}$ \\
$\mathrm{p}_{1} \mathrm{p}_{2}$ & $F_{12}$ & $-0.50^{\mathrm{d}}$ \\
$(1 / 2)\left(1-\cos 3 \alpha_{1}\right)$ & $V_{3,1}$ & $428.537(15)$ \\
$(1 / 2)\left(1-\cos 3 \alpha_{1}\right) \mathrm{J}^{2}$ & $V_{3,1 J}$ & $-0.0002903(90)$ \\
$(1 / 2)\left(1-\cos 3 \alpha_{2}\right)$ & $V_{3,2}$ & $819.97(25)$ \\
$\mathrm{J}_{\mathrm{z}} \mathrm{p}_{1}$ & $q_{1}$ & $0.590664(92)$ \\
$\mathrm{J}_{\mathrm{z}} \mathrm{p}_{2}$ & $q_{2}$ & $0.54^{\mathrm{d}}$ \\
$\mathrm{J}_{\mathrm{x}} \mathrm{p}_{1}$ & $r_{1}$ & $-0.053176(56)$ \\
$\mathrm{J}_{\mathrm{x}} \mathrm{p}_{2}$ & $r_{2}$ & $-0.0734^{\mathrm{d}}$ \\
\hline \hline
\end{tabular}

${ }^{\mathrm{a}}$ Operator which the parameter multiplies in the program.

${ }^{\mathrm{b}}$ Notation of eq. (6) and Table 3 of ref. [17], except for $A, B$, and $C$ where the prime was removed.

${ }^{c}$ Value of the parameter obtained from the final least-squares fit, with one standard uncertainty given in parentheses.

${ }^{\mathrm{d}}$ Fixed to values calculated from the structure and using the direction cosines from the XIAM code, see also text. Note that $F_{12}$ is named $f_{12}$ in eq. (6) of ref. [17]. 


\section{Figure captions}

Fig. 1: Broadband scan of methyl propionate in the range of 9.5 to $12.0 \mathrm{GHz}$.

The spectral range of $2.5 \mathrm{GHz}$ was covered by overlapping spectra with a step width of $0.25 \mathrm{MHz}$. For each single measurement 50 FIDs were co-added. The assigned transitions $J^{\prime}{ }^{\prime}{ }^{\prime}{ }^{\prime} c^{\prime} \leftarrow J^{\prime \prime}{ }{ }^{\prime \prime}{ }^{\prime} K c^{\prime}$, are marked with black points. A and $\mathrm{E}$ species refer to the larger splittings due to internal rotation of the methoxy methyl group. The intensities are given in arbitrary units on a logarithmic scale.

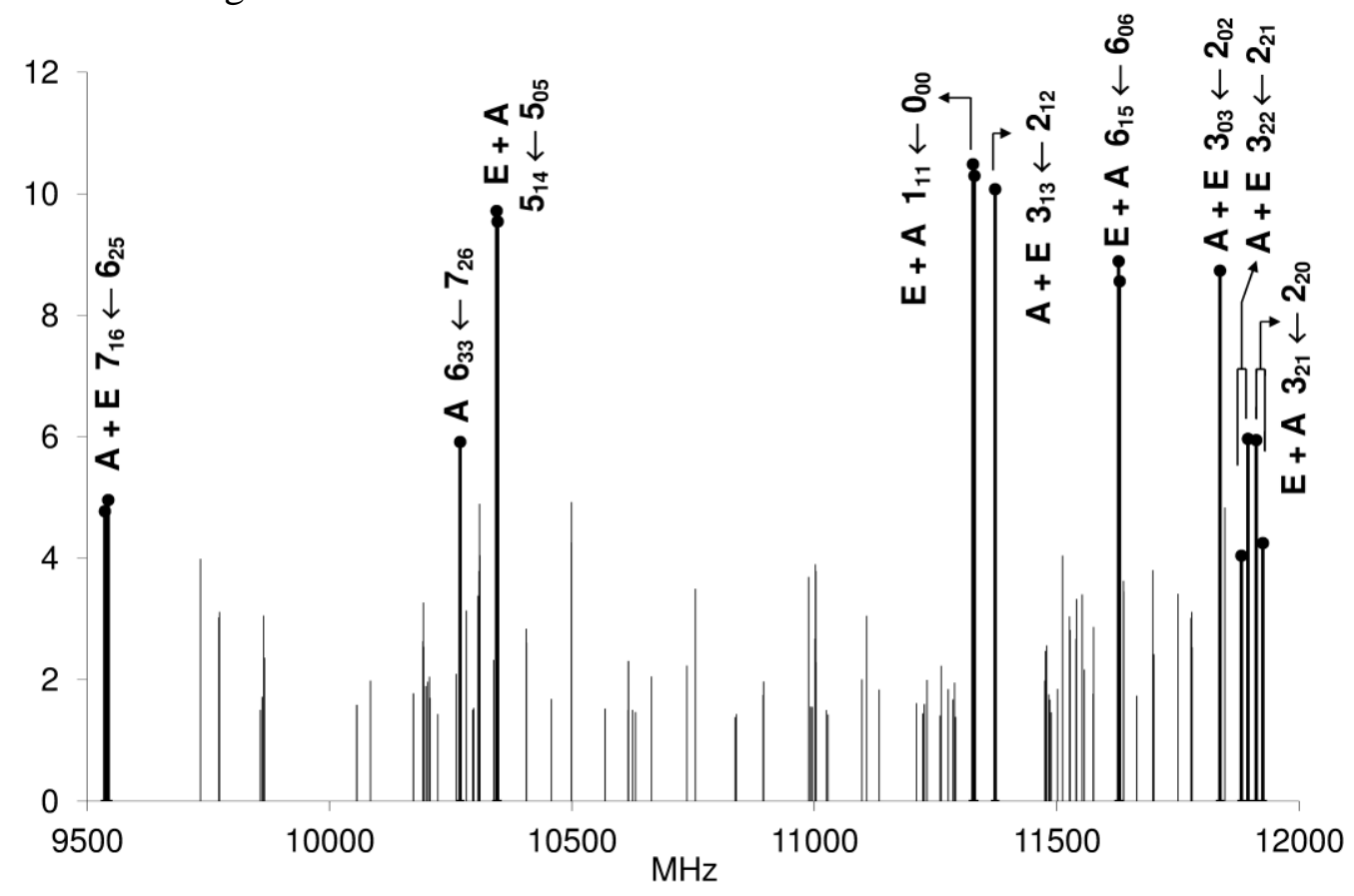

Fig. 2: Possible conformers of methyl propionate.<smiles>CCC(=O)OC</smiles>

trans $\mathrm{C}_{\mathrm{s}}$ conformer

(most stable)<smiles>CCC(=O)OC</smiles>

trans $C_{1}$ conformer (pair of enantiomers)<smiles>CCC(=O)OC</smiles>

cis $\mathrm{C}_{\mathrm{s}}$ conformer<smiles>CCC(=O)OC</smiles> 
Fig. 3: The potential curve of methyl propionate obtained by rotating the ethyl group around the $\mathrm{C}_{2}-\mathrm{C}_{3}$ bond (for atom number see Figure 2).

Different methods and basis sets were chosen. The relative energies with respect to the lowest energy conformer $(E=-306.9413386$ Hartree, -306.803613 Hartree, and -307.7994651 Hartree for the MP2/6-311++G(d,p), MP2/6-31G(d,p), and B3LYP/6-311++G(d,p) level, respectively) are given.

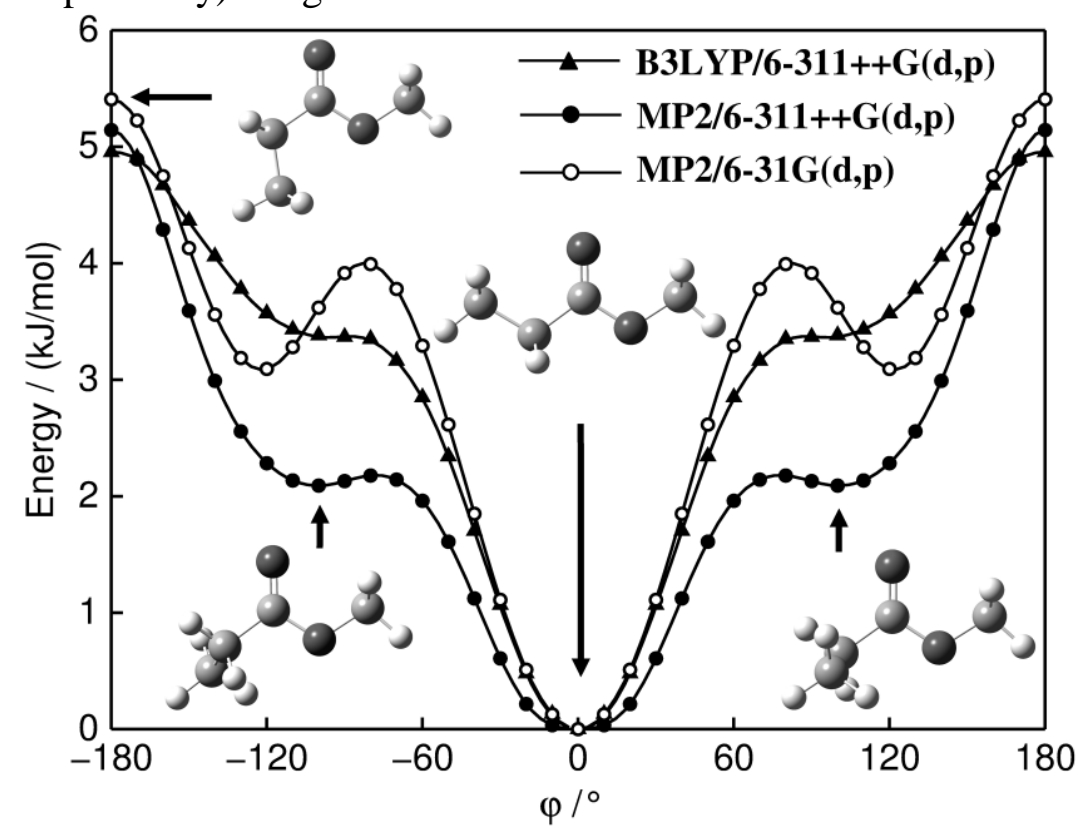

Fig. 4: Similar structure found in methyl propionate and some other molecules. In all cases, the $\mathrm{CH}-\mathrm{CH}_{2}-\mathrm{C}=\mathrm{O}$ bond has a low torsional force constant.<smiles>CCC(=O)OC</smiles>

methyl propionate<smiles>CCOC(=O)CC(C)C</smiles>

ethyl isovalerate<smiles>CCC(=O)CC</smiles>

diethyl ketone 
Fig. 5: A typical AA and AE species $2_{12} \leftarrow 1_{01}$ transition of methyl propionate. The experimental resolution was $4 \mathrm{kHz}$, the typical line width approximately $20 \mathrm{kHz}(\mathrm{FWHH})$. The large splitting is due to the Doppler effect (indicated by brackets). For this spectrum 53 FIDs were co-added.

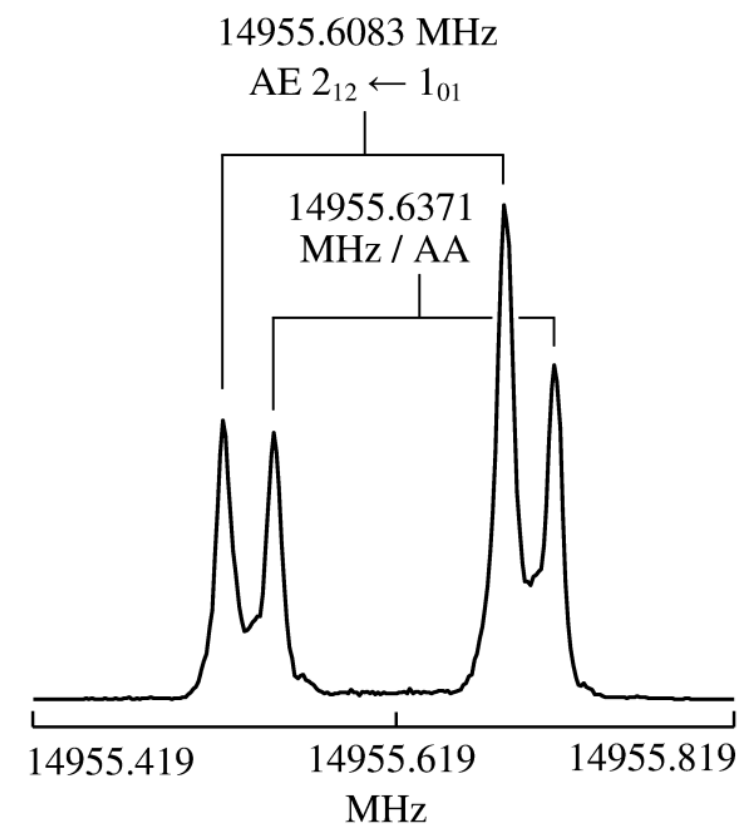

Fig. 6: A typical EA, EE, and EE* species $2{ }_{12} \leftarrow 1_{01}$ transition of methyl propionate. For this spectrum 53 FIDs were co-added.

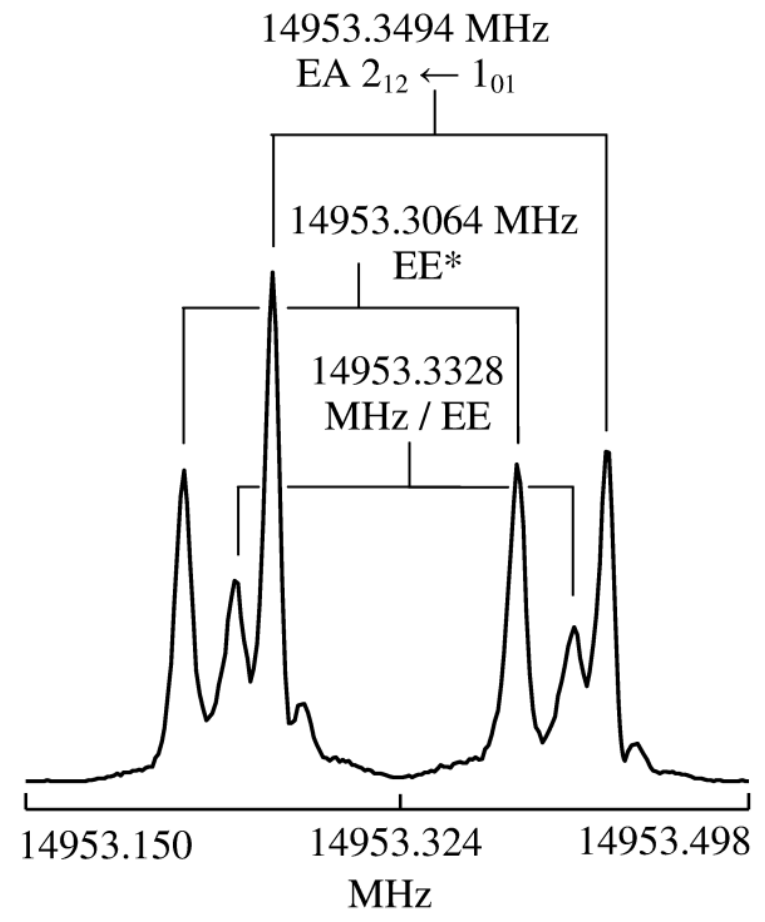

